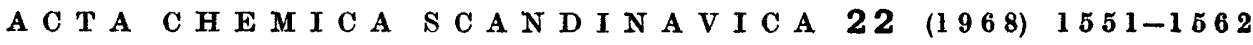

\title{
The Crystal Structure of $\mathrm{K}_{4} \mathrm{Mo}(\mathrm{CN})_{5} \mathrm{NO}$
}

\author{
DAG H. SVEDUNG and NILS.GÖTA VANNERBERG
}

\author{
Department of Inorganic Chemistry, University of Gothenburg and Chalmers Institute of \\ Technology, Gibraltargatan 5 A, Gothenburg, Sweden
}

\begin{abstract}
The crystal structure of $\mathrm{K}_{4} \mathrm{Mo}(\mathrm{CN})_{5} \mathrm{NO}$ has been determined by three dimensional X-ray methods. The space group of the structure of maximum degree of order is $\mathrm{Pbca}$ and the unit cell dimensions are $a=8.456, \AA, b=14.201 \AA$, and $c=21.276 \AA$.

The structure consists of ordered layers, parallel to the $x z$-plane, whose stacking is disordered. The molybdenum atoms are surrounded by six ligands which constitute a tetragonally distorted octahedron, the Mo-NO distance being only $1.95 \AA$ as compared with a mean Mo-CN distance of $2.13 \AA$.
\end{abstract}

T

he aim of this work was to support a research programme in progress at this Department into the crystal structures of the transition metal nitrosyls and to clarify the extensive discussion on the coordination of the molybdenum complex, $\mathrm{K}_{4} \mathrm{Mo}(\mathrm{CN})_{5} \mathrm{NO}$.

Among the structures which have already been determined at this Department are $\mathrm{K}_{3} \mathrm{Cr}(\mathrm{CN})_{5} \mathrm{NO}^{1}$ and $\mathrm{K}_{3} \mathrm{Mn}(\mathrm{CN})_{5} \mathrm{NO} \cdot 2 \mathrm{H}_{2} \mathrm{O}^{2}$ The purple pentacyanidonitrosyl complex obtained by reducing an alkaline solution of molybdate and cyanide with hydroxylamine has been formulated in various ways: ${ }^{3}$ namely, as a complex of molybdenum( $(0), \mathrm{K}_{4} \mathrm{Mo}(\mathrm{CN})_{5} \mathrm{NO}$, either with or without water of hydration, ${ }^{4-6}$ and as an eight-co-ordinated complex of molybdenum(II), $\mathrm{K}_{4} \mathrm{Mo}(\mathrm{CN})_{5}(\mathrm{OH})_{2} \mathrm{NO}^{?}$

\section{EXPERIMENTAL}

Potassium pentacyanidonitrosylmolybdate was prepared by the method of Hieber et al. $\mathrm{K}_{4} \mathrm{Mo}(\mathrm{CN})_{6}$ was first synthesised by reaction between molybdate and potassium cyanide in a saturated alkaline solution. Hydroxylamine was then added and the solution was heated on a water bath. Molybdenum hexacyanide reacts with hydroxylamine according to the equation:

$$
\mathrm{Mo}(\mathrm{CN})_{6}^{4-}+2 \mathrm{NH}_{2} \mathrm{OH} \longrightarrow \mathrm{Mo}(\mathrm{CN})_{5} \mathrm{NO}^{4-}+\mathrm{NH}_{3}+\mathrm{HCN}+\mathrm{H}_{2} \mathrm{O}
$$

The product was recrystallized several times and washed with absolute ethanol and ether. Suitable crystals were picked out of the mother liquor as soon as they had reached an appropriate size and immediately inserted in a closed capillary filled with nitrogen gas in order to avoid decomposition by air.

Acta Chem. Scand. 22 (1968) No. 5 
The compound was analysed for molybdenum potassium, and cyanide. Molybdenum was determined as lead molybdate, potassium by means of atomic absorption spectrophotometry, and cyanide gravimetrically as AgCN. The following results were obtained: (mean values)

$\begin{array}{lccr} & \% \text { Mo } & \% \mathbf{K} & \% \mathrm{CN} \\ \text { Experimental } & 22.5 & \mathbf{3 7 . 1} & \mathbf{2 9 . 2} \\ \text { Theoretical } & \mathbf{2 3 . 3} & \mathbf{3 7 . 9} & \mathbf{3 1 . 5}\end{array}$

\section{IR SPECTRA AND MAGNETIC PROPERTIES}

The IR spectra of the compound shows a low $\mathrm{N}-\mathrm{O}$ frequency which may be interpreted in terms of back donation from the central molybdenum atom which is favoured by the zero formal charge on the metal. ${ }^{5}$ The compound is diamagnetic.

\section{STRUCTURE DETERMINATION}

Single crystals of $\mathrm{K}_{4} \mathrm{Mo}(\mathrm{CN})_{5} \mathrm{NO}$ were rotated about the $a$ - and $b$-axis. In the rotation photographs taken when the crystal was rotated about the $a$-axis it was observed that each second layer line consisted of long weak streaks, thus indicating the presence of disorder in the structure.

Accurate cell dimensions were determined from Guinier powder photographs, using $\mathrm{Pb}\left(\mathrm{NO}_{3}\right)_{2}$ as an internal standard and $\mathrm{CuK \alpha _{1 }}$ radiation $\left[\lambda\left(\mathrm{Cu} K \alpha_{1}\right)=1.54050 \AA\right]$. Forty reflections were indexed with the Algol Programme Xalg Powder ${ }^{8}$ and the same programme was used to refine the cell constants. The elementary cell dimensions were found to be:

$$
\begin{aligned}
& a=8.456 \pm 0.002 \AA \\
& b=14.201 \pm 0.003 \AA \\
& c=21.276 \pm 0.003 \AA \\
& V=2554.4 \AA^{3}
\end{aligned}
$$

Observed and calculated values of $\sin ^{2} \theta$ and the corresponding intensities of the reflections are listed in Table 1. The density was determined to be 2.08 $\mathrm{g} / \mathrm{cm}^{3}$, indicating eight formula units per unit cell.

The Weissenberg layers $0 k l-8 k l$ (531 reflections) and $h 0 l-h 2 l$ (72 reflections) were registered using $M o K \alpha$ radiation and $\mathrm{Zr}$-filters.

The nomenclature used in this paper is in accordance with that of the book Lehrgang über OD-strukturen by K. Dornberger-Schiff. ${ }^{15}$ The odd layer line reflections $(1 \eta l, 3 \eta l, 5 \eta l)$ appeared as long streaks indicating disorder in the direction of the $y$-axis, (Fig. 1). The intensities of these reflections were determined at the reciprocal lattice points where there were always more or less well-defined intensity maxima. The accuracy in the determination of these 228 reflections was consequently low. 
Table 1. Powder data.

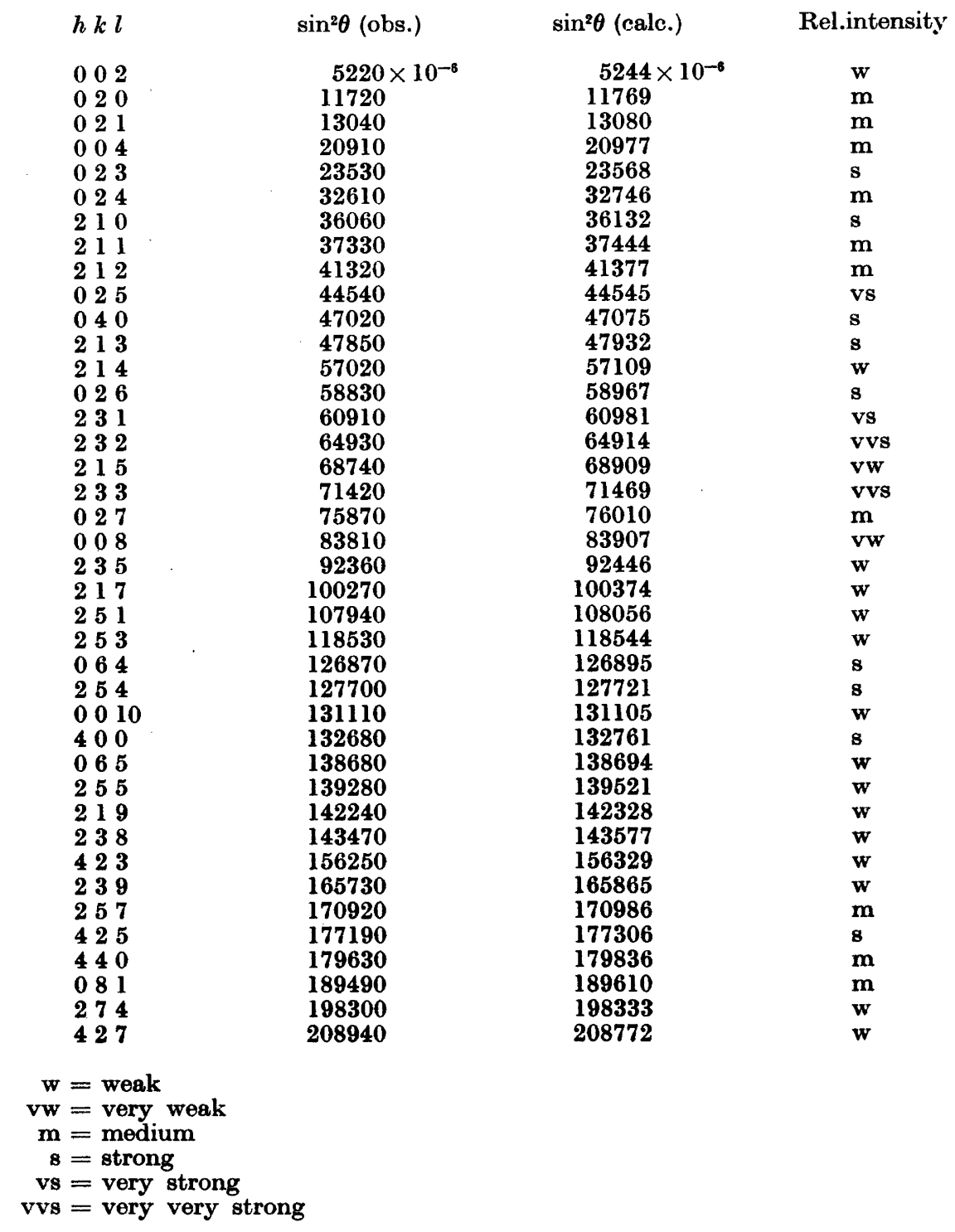

The systematic absences may be summarized as follows:

(i) (hnl) missing for $h=2 H$ if $\eta \neq k$

(ii) ( $h \eta 0)$ missing for $h=2 n+1$

(iii) (hol) missing for $l=2 n+1$

(iv) ( $H K l$ ) missing for $H+K=2 n+1$

Acta Chem. Scand. 22 (1968) No. 5 


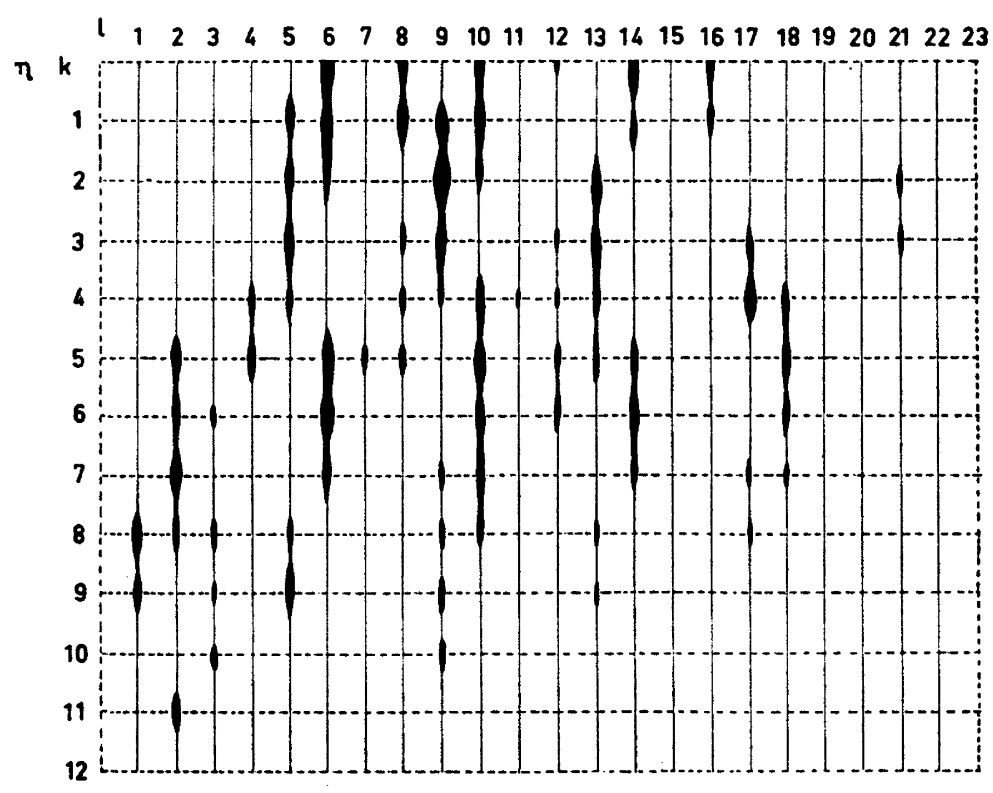

Fig. 1. The reciprocal lattice zone $(1 \eta l)$.

A structure denoted $\hat{\varrho}(x y z)$ which is related to the true structure by:

$$
\hat{\varrho}(x, y, z)=\varrho(x, y, z)+\varrho\left(x+\frac{1}{2}, y, z\right)
$$

is thus, according to (i) and (iv), periodic with translation vectors $\vec{A}=\vec{a} / 2$, $\vec{B}=\vec{b}$ and $\vec{C}=\vec{c}$. This superposition structure shows $C$-face centering, whereas the true structure is not periodic in the $b$-direction, but periodic in the $a$ and $c$-directions with translational vectors $\vec{a}$ and $\vec{c}$.

According to (ii) for every atom in $(x y z)$ there exists an identical atom in $\left(x+\frac{1}{2}, y, z^{\prime}\right)$, which, because the $y$-coordinates are equal, must belong to the same layer. We may thus assume that these positions are related by an $a$ glide perpendicular to $c$ within the layer. According to (iii) for every atom in $(x y z)$ there exists an identical atom in $\left(x, y^{\prime}, z+\frac{1}{2}\right)$ and this is true whether or not the packing of the layers is disordered. Thus the two atoms linked in this way must belong to the same layer, and the relationship between them corresponds to a $c$-glide perpendicular to $b$. The minimum symmetry of a single layer is therefore $P 2_{1}(c) a$, but $P m(c) a$ is also possible.

The $C$-face centering of the superposition structure shows that adjace't layers are linked by the translations $(\vec{a} / 4)+(\vec{b} / 2)$ or $-(\vec{a} / 4)+(\vec{b} / 2)$ and $\overrightarrow{b_{0}}=\vec{b} / 2$, where $\vec{b}_{0}$ is the distance between two successive layers. The periodic structure of maximum degree of order (MDO-structure) consisting of a "zigzag" of layers would have the space group $P 2_{1} c a$ or $P b c a$ for the OD-groupoid family 
of lower or higher symmetry, respectively. The symbols of these OD-groupoid families are:

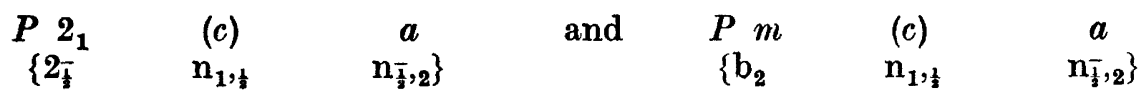

respectively. The structure of maximum degree of order in which the layers are packed obliquely over one another would have space group symmetry $P 2_{1} / a$ or $P a$, with $\left.\overrightarrow{a^{\prime}}=\vec{a}, \overrightarrow{b^{\prime}}=(\vec{b} / 2)+\overrightarrow{(a} / 4\right)$ and $\overrightarrow{c^{\prime}}=\vec{c}$. (c-axis unique).

The structure determination was at first based on the superposition structure which according to the systematic absences belonged to the space group $\mathrm{Cmcm}$, No. 63. From a three dimensional Patterson synthesis it was then possible to locate all the heavy atoms. It was, however, evident that one molybdenum atom and one potassium atom must be placed in the same eightfold position, and in subsequent calculations a scattering factor was employed for this position which was the mean of the atomic scattering factors of potassium and molybdenum. With the aid of the heavy atom positions the signs of the structure factors could be determined, and the positions of the light atoms were then obtained from a three-dimensional Fourier synthesis performed with these signs.

The positions of the light atoms were refined by difference syntheses, and after several cycles of least squares refinement an $R$-value of 0.13 was obtained. Owing to the disorder in the structure, there is overlap of the ligand atoms near the mirror plane perpendicular to the $c$-axis so that it was not at this stage possible to identify the nitrosyl group, and all the ligands were therefore treated as cyanide groups (Fig. 2). Similar difficulties were encountered by Vannerberg during the study of the structure of $\mathrm{K}_{3} \mathrm{Cr}(\mathrm{CN})_{5} \mathrm{NO}{ }^{1}$

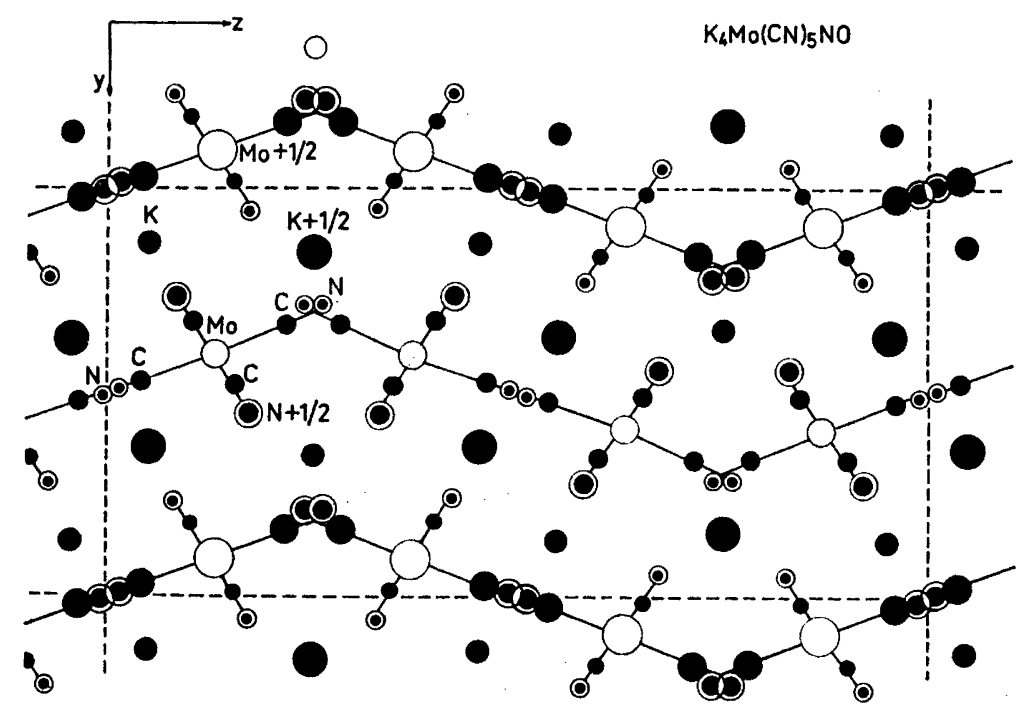

Fig. 2. The superposition structure, spacegroup, Cmcm; No. 63 . Acta Chem. Scand. 22 (1968) No. 5 
A three dimensional Patterson synthesis based on the intensity data of the odd layer lines only, for $\eta=k$, shows some extremely valuable features. It reveals a Patterson function of a single layer together with its mirror image in the plane $x=0$. This function is overlapped by a similar function which corresponds to a periodicity of $2 b$ and an antitranslation $a / 2$, as only odd $h$-values $(h=2 n+1)$ were used. This means that the influence of each second layer has disappeared completely and this fact makes the Patterson function extremely easy to interpret. It thus became possible, for instance, to determine the positions of the molybdenum and potassium atoms which had previously overlapped in the superposition structure.

The structure was then refined on the assumption that it was most similar to the MDO-structure belonging to the space group $\mathrm{Pbca}$, No. 61. That this is the most likely structure could be concluded from the positions of the intensity maxima of the long reflection streaks of index $1 \eta l, 3 \eta l$ and $5 \eta l$.

All atoms could now be placed in different crystallographic eightfold positions which eliminated, among other things, the previous artificial overlap of certain ligand groups in the Mo-K-Mo chains along the $x$-and $z$-axes, as illustrated in Fig. 3.

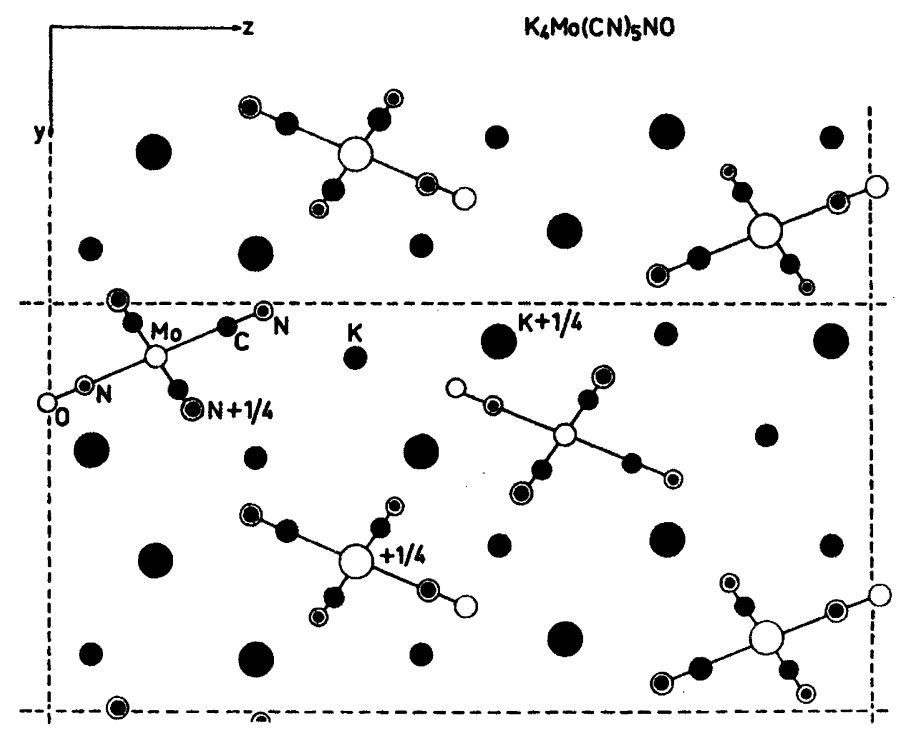

Fig. 3. The structure of maximum degree of order, spacegroup, Pbca, No. 61 .

After a few cycles of isotropic least squares refinement the $R$-value converged to 0.115 and a calculation of bond distances and angles revealed five cyanide groups at approximately equal distances and one group at a considerably shorter distance around each molybdenum atom. The atoms of the latter group were labeled nitrogen and oxygen (Figs. 3 and 4). A separate 
Table 2. Fractional atomic parameters for $\mathrm{K}_{4} \mathrm{Mo}[\mathrm{CN}]_{5} \mathrm{NO}$ and their standard deviations. All atoms are in position $c$.

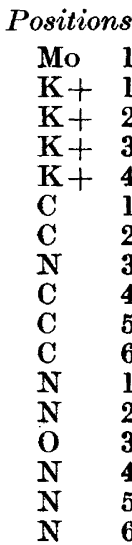

0.87500
0.87500
0.12500
0.87500
0.87500
0.04953
0.05064
0.87500
0.87500
0.69908
0.69759
0.14276
0.14859
0.87500
0.87500
0.60064
0.60247

0.16370

0.88635

0.90332

0.88462

0.14946

0.06502

0.25487

0.22524

0.08410

0.06608

0.25501

0.01194

0.30965

0.25720

0.03852

0.01430

0.30882

Standard deviations

$\begin{array}{ll}\mathbf{M o} & \mathbf{1} \\ \mathbf{K} & \mathbf{1} \\ \mathbf{K}+ & \mathbf{2} \\ \mathbf{K}+\mathbf{3} \\ \mathbf{K}+\mathbf{4} \\ \mathbf{C} & \mathbf{1} \\ \mathbf{C} & \mathbf{2} \\ \mathbf{N} & \mathbf{3} \\ \mathbf{C} & \mathbf{4} \\ \mathbf{C} & \mathbf{5} \\ \mathbf{C} & \mathbf{6} \\ \mathbf{N} & \mathbf{1} \\ \mathbf{N} & \mathbf{2} \\ \mathbf{O} & \mathbf{3} \\ \mathbf{N} & \mathbf{4} \\ \mathbf{N} & \mathbf{5} \\ \mathbf{N} & \mathbf{6}\end{array}$

0.00000

0.00000

0.00000

0.00000

0.00000

0.00829

0.00644

$\mathbf{0 . 0 0 0 0 0}$

0.00000

0.00610

0.00755

0.00490

0.00510

0.00000

0.00000

0.00515

0.00547
0.00036

0.00084

0.00054

0.00081

0.00066

0.00325

0.00382

0.00230

0.00298

0.00397

0.00452

$\mathbf{0 . 0 0 4 3 8}$

0.00307

0.00236

0.00191

0.00301

0.00331
0.12301

0.04860

0.25000

0.45440

0.35851

0.09405

0.15831

0.04097

0.21191

0.09422

0.15752

$\mathbf{0 . 0 7 6 2 0}$

0.17129

0.98735

0.25782

0.07586

0.17119

0.00021

$\mathbf{0 . 0 0 0 4 5}$

0.00000

0.00044

0.00035

0.00274

0.00205

0.00148

0.00203

0.00208

0.00234

0.00210

0.00167

0.00128

0.00170

0.00157

0.00176

Table 3. Bond distances in $\mathrm{K}_{4} \mathrm{Mo}(\mathrm{CN})_{5} \mathrm{NO}$.

$\begin{array}{ll}M_{1}(1)-C_{1}(1) & 2.13 \pm 0.06 \AA \\ M o_{1}(1)-C_{2}(1) & 2.11 \pm 0.05 \\ M o_{1}(1)-N_{3}(1) & 1.95 \pm 0.03 \\ M o_{1}(1)-C_{4}(1) & 2.20 \pm 0.04 \\ M o_{1}(1)-C_{5}(1) & 2.12 \pm 0.05 \\ M o_{1}(1)-C_{6}(1) & 2.11 \pm 0.06 \\ C_{1}(1)-N_{1}(1) & 1.15 \pm 0.08 \\ C_{2}(1)-N_{2}(1) & 1.17 \pm 0.07 \\ N_{3}(1)-O_{3}(1) & 1.23 \pm 0.04 \\ C_{4}(1)-N_{4}(1) & 1.17 \pm 0.05 \\ C_{5}(1)-N_{5}(1) & 1.18 \pm 0.07 \\ C_{6}(1)-N_{6}(1) & 1.15 \pm 0.08\end{array}$

$$
\begin{aligned}
& K_{2}(1)-N_{2}(3) \\
& K_{2}(1)-N_{2}(6) \\
& K_{2}(1)-N_{4}(1) \\
& K_{2}(1)-N_{4}(8) \\
& K_{2}(1)-N_{8}(3) \\
& K_{2}(1)-N_{6}(6) \\
& K_{4}(1)-N_{1}(8) \\
& K_{4}(1)-N_{2}(8) \\
& K_{4}(1)-O_{3}(7) \\
& K_{4}(1)-N_{4}(1) \\
& K_{4}(1)-N_{5}(8) \\
& K_{1}(1)-N_{6}(8)
\end{aligned}
$$

$3.15 \pm 0.04 \AA$

$2.87+0.04$

$2.86 \pm 0.02$

$2.86+0.02$

$3.15 \pm 0.04$

$2.88 \pm 0.04$

$3.10 \pm 0.05$

$3.04 \pm 0.04$

$3.04 \pm 0.03$

$2.66 \pm 0.03$

$3.05 \pm 0.04$

$3.04 \pm 0.05$

Acta Chem. Scand. 22 (1968) No. 5 


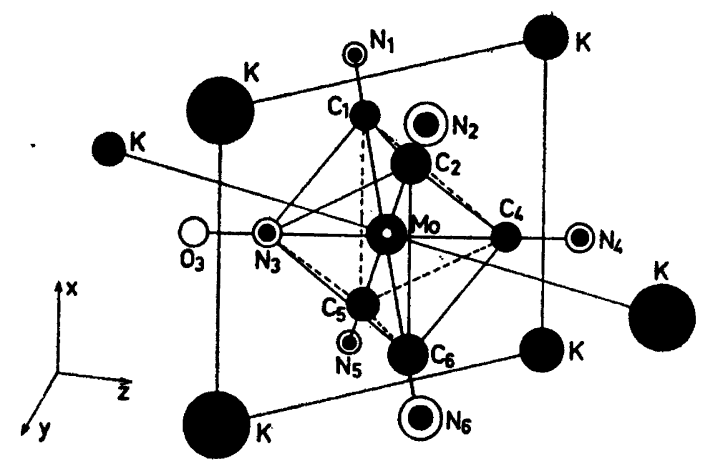

Fig. 4. The molybdenum complex and the surrounding potassium octahedron.

Table 4. Bond angles in $\mathrm{K}_{4} \mathrm{Mo}(\mathrm{CN})_{5} \mathrm{NO}$.

$$
\begin{aligned}
& M_{1}(1)-C_{1}(1)-N_{1}(1) \\
& M_{1}(1)-C_{8}(1)-N_{2}(1) \\
& M_{1}(1)-N_{3}(1)-O_{3}(1) \\
& M_{1}(1)-C_{4}(1)-N_{4}(1) \\
& M_{1}(1)-C_{5}(1)-N_{5}(1) \\
& M_{1}(1)-C_{8}(1)-N_{6}(1) \\
& N_{3}(1)-M_{1}(1)-N_{1}(1) \\
& N_{3}(1)-M_{1}(1)-N_{2}(1) \\
& N_{3}(1)-M_{1}(1)-N_{4}(1) \\
& N_{3}(1)-M_{1}(1)-N_{5}(1) \\
& N_{3}(1)-M_{1}(1)-N_{6}(1) \\
& N_{1}(8)-K_{4}(1)-N_{2}(8) \\
& N_{1}(8)-K_{4}(1)-O_{3}(7) \\
& N_{1}(8)-K_{4}(1)-N_{4}(1) \\
& N_{1}(8)-K_{4}(1)-N_{5}(8) \\
& N_{1}(8)-K_{4}(1)-N_{6}(8)
\end{aligned}
$$

$177.6 \pm 5.0^{\circ}$

$172.5 \pm 3.9$

$175.1 \pm 2.9$

$177.3 \pm 3.5$

$177.0 \pm 4.1$

$173.8 \pm 4.6$

$91.3 \pm 1.1$

$89.9 \pm 0.9$

$174.8 \pm 1.1$

$90.9 \pm 0.9$

$89.9 \pm 1.0$

$99.6 \pm 1.2$

$82.6 \pm 1.1$

$89.3 \pm 1.1$

$78.1 \pm 1.2$

$164.7 \pm 1.2$

treatment of the reflections of the even layer lines only yielded an $R$-factor of 0.067 thus emphasizing the inferior quality of the intensity data obtained from the odd layer lines. The observed and calculated structure factors are given in Table 6 , the atomic parameters in Table 2 , and the most interesting bond distances and angles in Tables 3 and 4.

All calculations, including the Lorentz and polarisation correction, were performed on the SAAB D21 computer at the University Computing Center, Gothenburg, using programmes written by Abrahamsson et al.$^{9-12}$

\section{DESCRIPTION OF THE STRUCTURE}

The structure consists of ordered layers parallel to the $x z$-plane. In such layers molybdenum complex ions and potassium ions alternate along the $x$ - and $z$-axes. 
The stacking of the layers is disordered.

The molybdenum atoms are surrounded by six ligands, five cyanide groups and one nitrosyl group, constituting a tetragonally distorted octahedron. The Mo-NO distance was found to be only $1.95 \AA$ as compared with a mean Mo-CN distance of $2.13 \AA$. The distance between the molybdenum atom and the cyanide group diametrically opposite the nitrosyl group is $2.20 \AA$. The standard deviations of the positions of the four cyanide groups in the plane perpendicular to the $y z$-plane, do not exclude the possibility of a mirror plane, in this case a partial symmetry element, perpendicular to the $a$-axis through the molybdenum atom.

The potassium atoms $\left(\mathrm{K}_{1}, \mathrm{~K}_{3}\right.$, and $\left.\mathrm{K}_{4}\right)$ are surrounded by five nitrogen atoms and one oxygen atom in the form of a distorted octahedron and the potassium atoms $\left(\mathbf{K}_{2}\right)$ are surrounded by six nitrogen atoms which constitute a trigonal prism. The molybdenum complex ions are enclosed within distorted octahedra of potassium ions (Fig. 4).

The fractional atomic parameters in Table 2 refer to an ordered structure belonging to the space group Pbca. A final Fourier difference synthesis indicated that no water of hydration was present in the structure.

\section{DISCUSSION OF THE STRUCTURE}

Because of the disorder in the structure the different reflection intensities are less sensitive than is usual to the positions of the light atoms. Despite this, it is obvious that the most probable crystal structure determined reveals a tetragonally distorted complex ion similar to that found in $\mathrm{Mn}(\mathrm{CN})_{5} \mathrm{NO}^{3-}$ and in $\mathrm{Fe}(\mathrm{CN})_{5} \mathrm{NO}^{2-} .{ }^{14}$

If inner electrons are disregarded, $\mathrm{Mo}(\mathrm{CN})_{5} \mathrm{NO}^{4-}$ is iso-electronic with the above-mentioned ions. Their crystal structures (e.g. the short M-NO bond), their magnetic and optical properties (e.g. the diamagnetism and the low $\mathrm{N}-\mathrm{O}$ IR-frequency) may all be successfully interpreted on the basis of the bonding scheme presented by Ballhausen and Gray. ${ }^{13}$

Table 5 shows a comparison of some interesting geometrical data concerning the pentacyanidonitrosyl-complexes of manganese, iron, and molybdenum.

Table 5. Some geometrical properties of the pentacyanidonitrosyl-complexes of iron, manganese and molybdenum.

$\begin{array}{llllll} & (\mathrm{M}-\mathrm{CN}) & (\mathrm{M}-\mathrm{NO}) & (\mathrm{C}-\mathrm{N}) & (\mathrm{N}-\mathrm{O}) & \begin{array}{c}(\mathrm{M}-\mathrm{CN})- \\ (\mathrm{M}-\mathrm{NO})\end{array} \\ \mathrm{Fe}(\mathrm{CN})_{5} \mathrm{NO}^{2-} & 1.91 \AA & 1.63 \AA & 1.16 \AA & 1.13 \AA & 0.28 \AA \\ \mathrm{Mn}(\mathrm{CN})_{5} \mathrm{NO}^{3-} & 1.98 & 1.66 & 1.16 & 1.21 & 0.32 \\ \mathrm{Mo}(\mathrm{CN})_{5} \mathrm{NO}^{4-} & 2.13 & 1.95 & 1.16 & 1.23 & 0.18\end{array}$


Table 6. The observed and calculated structure factors.

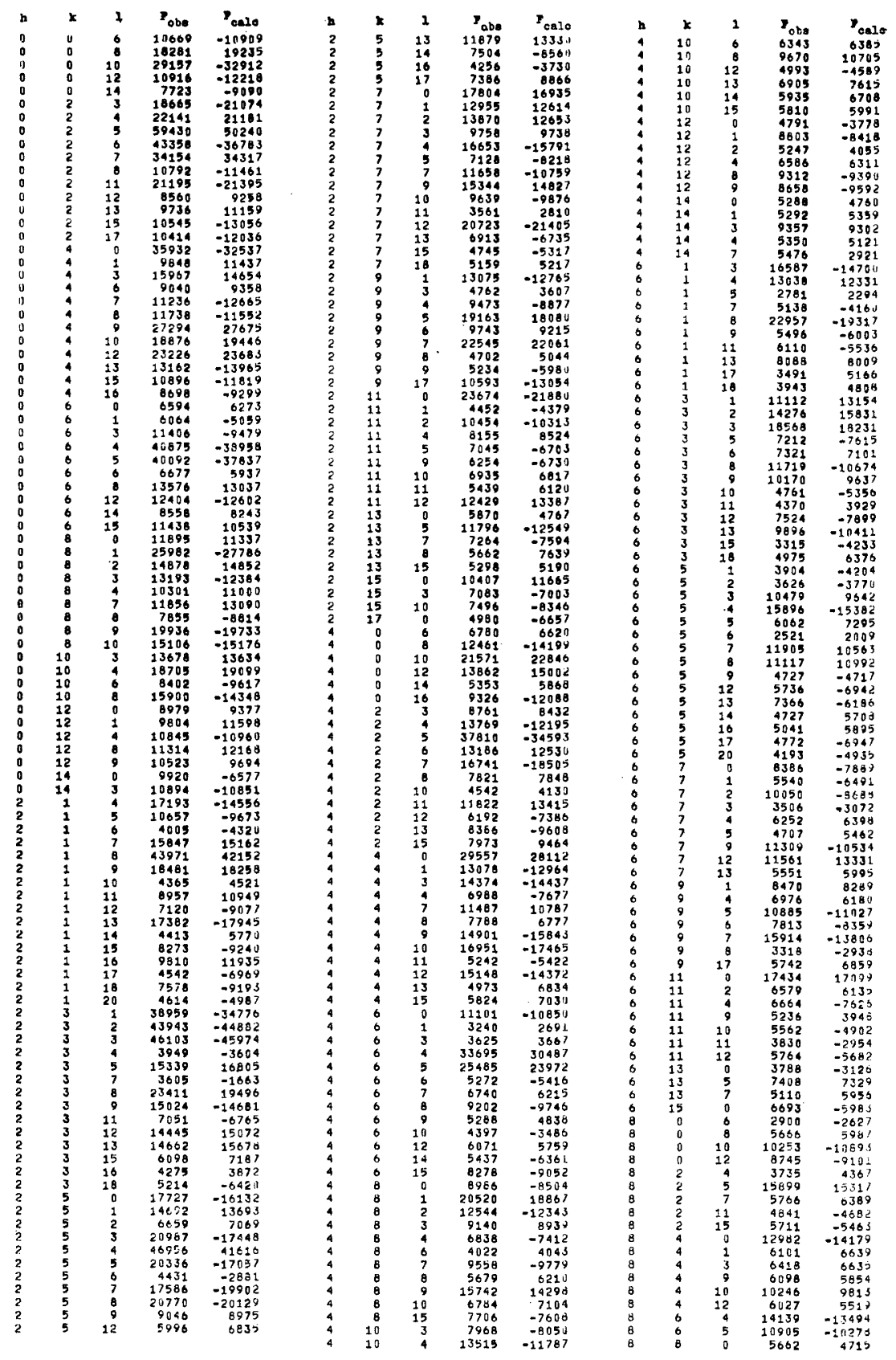


Table 6. Continued.
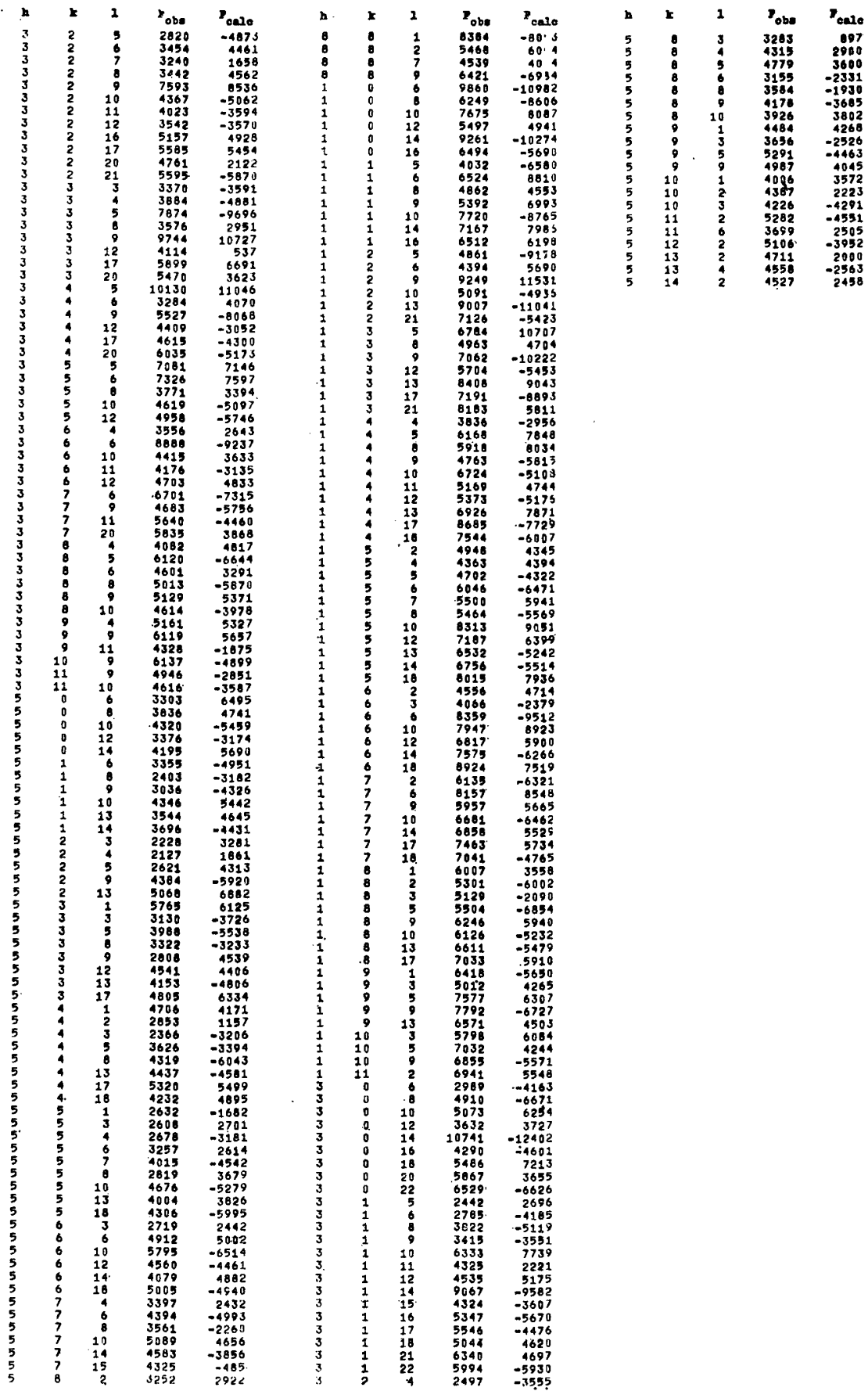
Acknowledgements. The authors wish to thank Mrs. Margareta Bieth for her readiness to help, especially with the technical details. We also wish to thank Prof. Georg Lundgren of this Department and Prof. Dr. K. Dornberger-Schiff of the German Academy of Science for valuable discussions. Finally we should like to thank Fil.lic. Susan Jagner for revising the English text, and the Swedish Natural Science Research Council (Contract No. $2286-11)$ whose financial support has made this work possible.

\section{REFERENCES}

1. Vannerberg, N.-G. Acta Chem. Scand. 20 (1966) 1571.

2. Tullberg, A. and Vannerberg, N.-G. Acta Chem. Scand. 21 (1967) 1462.

3. Mitchell, P. C. H. Coord. Chem. Rev. 1 (1966) 315.

4. Hieber, W., Nast, R. and Gehring, G. Z. Anorg. Chem. 256 (1948) 169.

5. Riley, R. F. and Ho, L. J. Inorg. Nucl. Chem. 24 (1962) 1121.

6. Jakob, W., Hejmo, E. and Kanas, A. Roczniki Chem. 37 (1963) 703.

7. Griffith, W. P., Lewis, J. and Wilkinson, G. J. Chem. Soc. 1959872.

8. Lindqvist, O. and Wengelin, F. To be published.

9. Abrahamsson, S. and Larsson, K. Arkiv Kemi 24 (1965) 383.

10. Abrahamsson, S. Arkiv Kemi 24 (1965) 389.

11. Aleby, S. Arkiv Kemi 24 (1965) 395.

12. Larsson, K. Arkiv Kemi 23 (1964) 17.

13. Ballhausen, C. J. and Gray, H. B. Inorg. Chem. 2 (1963) 426.

14. Manoharan, P. T. and Hamilton, W. C. Inorg. Chem. 2 (1963) 1043.

15. Dornberger-Schiff, K. Lehrgang über OD-Strukturen, Akademie-Verlag, Berlin 1966.

Received January 3, 1968. 